\title{
EDITORIAL LIVING IN A CONTRADICTORY WORLD: CPA'S ADMISSION TO SSCI
}

On May 8, 2015, a little more than two years after having sent an application to Thomson Reuters, the editorial team of Critical Perspectives on Accounting (CPA) learned that the journal was admitted to the Social Sciences Citation Index (SSCI) - the database that produces impact factor measures. This was a lengthy and frustrating process since, after we applied, there was complete silence from Thomson Reuters. Once we were provided with the information regarding our inclusion, we initially felt relieved since several other accounting journals had, recently, been incorporated into SSCI and we thought that CPA's exclusion would, in the long run, translate into a competitive disadvantage in terms of attracting new high quality submissions and also disadvantage the careers of CPA authors.

After a few hours, though, we developed a more nuanced interpretation of what may appear, at first sight, to be a tangible indication of "success". After all, as accounting scholars, we know about the intricacies ensuing from the logic of performance measurement, which are deeply ingrained in the ebb and flow of everyday life. These measures are extraordinarily influential, especially through the constellation of visibility and invisibility axes which they sustain (Jeacle, 2012; Miller \& O'Leary, 1987; Robson, 1992). This influence is rarely emancipatory (Funnell, 1998; Roberts, 1991).

Through this editorial, we seek to make CPA readers aware of a more nuanced interpretation concerning the journal's admission to SSCI, which is centered on the pervasiveness of social life's contradictions. In a way, CPA's inclusion constitutes a promising landmark that may positively impact the future development of the journal yet paradoxically, it reproduces a performance measurement regime that some observers have described as biased, even tyrannical (Willmott, 2011). One of our points is that the contradictions of social life constitute fascinating objects of study for critical inquiry although researchers need to recognize that contradictions are often firmly ingrained in communities and therefore unlikely to be easily resolved or mitigated. In other words, nothing prevents stakeholders' reflexivity from being stimulated and enhanced through the dissemination of critical research studies that examine the power of established institutions (such as journal rankings) and their underlying contradictions, including the deteriorating effects they engender across social communities.

Our initial celebratory feelings were short-lived since CPA has, over the years, contributed to the establishment of a body of knowledge that questions the institutionalization of journal rankings such as SSCI and brings to the fore their subtle and not-so-subtle effects. A special section devoted to the sustainability of accounting academia was recently published in the journal with several articles bringing to the fore a range of negative effects ensuing from academics' excessive reliance and docility vis-à-vis journal ranking practices (Humphrey \& Gendron, 2015). Rankings are viewed as engendering a climate of insecurity, especially for doctoral students and young academics (Malsch \& Tessier, 2015; Prasad, 2015; Raineri, 2015), while creating and/or amplifying a hierarchy in terms of research styles - in that some specific objects of study, epistemologies and methodologies are increasingly privileged at the expense of others which tend to be ignored in highly ranked journals (Komori, 2015; Messner, 2015; Pelger \& Grottke, 2015). In particular, highly ranked journals tend to support the status quo and their research methodologies are accordingly, often functionalist and positivist. Further, rankings are associated with intellectual stagnation in accounting academia - at best, they slow down the emergence of new and innovative ideas in the field (Gendron, 2015). These important issues echo a stream of concerns in a growing 
number of articles published in other journals, both within and beyond the accounting literature (Adler \& Harzing, 2009; Alvesson \& Sandberg, 2013, 2014; Gendron, 2008; Hopwood, 2007; Willmott, 2011).

The difficulties involved in modifying a regime of institutionalized beliefs and practices (or even moderating its influence) are recognized in the literature on journal rankings (Adler \& Harzing, 2009; Hermanson, 2015). According to Tuttle and Dillard (2007, p. 404), it is important to:

[...] recognize that the forces at play here do not represent a conspiracy to dominate [academic accounting research]. Rather, rational individuals are reacting in rational ways to institutional forces that act on them. Hence, solutions must be institutional; individuals acting alone cannot bring it about (e.g., individual journal editors or AAA [American Accounting Association] presidents).

Importantly, research indicates that the reproductive power of journal rankings relate to their underlying contradictions, in that rankings both seduce and constrain (Sauder \& Espeland, 2009; Gendron, 2008). As elegantly explicated by Roberts (2009), over time we, as individuals, may come to appreciate and even enjoy "transparent" measurements (such as rankings) and the role they play in constituting reputations and presenting gratifying images of the self - this seduction is all the more influential since disciplinary constraints tend to operate when one fails to perform, or fears being seen by others as not performing adequately (Sauder \& Espeland, 2009). Thus, the rankings' contradictory articulations, which permeate our everyday lives, make their abandonment a particularly challenging endeavor. In a way, we are all schizophrenic regarding journal rankings, which are perceived and acted upon, in the academic field, as being both a pragmatic indispensability and a deplorable calamity. However, this is no reason for being complacent and passive regarding the panoply of detrimental effects ensuing from the institutionalization of formalized journal lists and rankings - such as SSCI. For example, the extreme form of hierarchical elitism sustained through the FT45 ranking, which marginalizes and ignores hundreds of business journals, should be vigorously denounced and combated.

In a less pronounced way than the FT45 ranking, SSCI also contributes to the spread of excessive performance measurement in academia. Its power is sustained through contradictions that it helps to generate; this is a key feature of the way it is institutionalized in the field. Fundamentally speaking, Thomson Reuter's SSCI is predicated on the view that $20 \%$ of research articles account for $80 \%$ of the citations (Garfield, 2006). This claim is, by and large, considered as "factual" reflecting the popular " $80 / 20$ rule" (p. 91). Yet SSCI's presumption ignores the performativity effects which are engendered once the Index is used by a variety of people in the field, thereby accentuating (or creating) the reality it was supposed to describe. The Index is particularly contradictory in terms of the tension between visibility and invisibility. In light of its calculation protocol, the impact factor of any journal on the Index can easily be compiled and verified. However, this calculation is circumscribed to citations in journals that are part of the Index. As such, it excludes citations in other journals, whose role in the production of knowledge is, therefore, assumed as being marginal, even trivial. Publications through books or edited collections are also omitted. That being said, one of the greatest contrasts pertaining to the "transparency" of impact factor calculations is the obscurity of the process by which new journal applications are considered and evaluated at Thomson Reuters. Given that inclusion decisions are made behind closed doors, this implies that judgments regarding the " $80 / 20$ rule" may not be that obvious contrary to the factual statement promoted by Thomson Reuters in order to justify the 
existence of the Index. The crux of the matter is that SSCI is characterized by a deep contrast between transparency and obscurity, akin to any set of performance measurement indicators. The Index is certainly not a divine and transparent revelation of what matters in terms of knowledge being produced in the social sciences - although the ascendancy that it exerts over contemporary academia may leave one wondering how it is perceived and acted upon by the community.

Is there a way of resolving these deeply-ingrained contradictions? Can they at least be mitigated? Can the schizophrenic attitude that many of us have vis-à-vis journal rankings, which are simultaneously venerated and demonized, but also desired, be overcome? What should be the attitude of critical research scholars concerning the institutions of journal rankings and their underlying contradictions? Crucially, is there an enemy which should be the target of our recriminations and criticisms - or is the power of journal rankings a discursively-embedded phenomenon, widely diffused in society throughout a multitude of more or less solid points of support? One should not forget that Thomson Reuters is a large corporation (2014 turnover, US\$12.6 billion). It portrays itself as the world's leading source of intelligent information for businesses and professionals. In this context, SSCI, profitable or not, carries huge symbolic value. Nonetheless, the contradictory feelings engendered by performance metrics need to be understood. Is the enemy that we should combat embedded in every one of us?

Several lines of thought in the social sciences suggest that contradictions constitute an inescapable feature of social life. Meaning oftentimes is articulated through contrast; for instance, although "good" is frequently presented as the opposite of "bad", the existence of "good" inevitably depends upon and intertwines with that of "bad". Macintosh (2002, p. 18) states that, "one side is nothing without its self-same opposite". This line of thought has been developed, to some extent, in studies on the "rivalry" between the professional and commercial logics in the field of auditing (Malsch \& Gendron, 2013), and between the social purpose logic and that of economics in the context of non-governmental organizations (Rahaman, Neu, \& Everett, 2010). From a different analytical perspective, René Girard (1965), through the concept of mimetic rivalry, argues that contradiction is at the heart of the way in which humans make sense of and interpret the world. The relationship between a sense-making individual and another individual (who somehow comes to be perceived as a "model") may be characterized, at once, by fascination, desire and rivalry (Guénin-Paracini \& Gendron, 2010). "Since we identify and compete with others, they become simultaneously our models and [our] rivals." (Alvesson, 2013, p. 7)

The point being made through this brief theoretical excursion is that CPA's contradictory attitude regarding its inclusion on SSCI is far from idiosyncratic. Contradictions may be deeply intertwined in the way in which human beings make sense of the world and communicate meaning. Contradictions abound in everyday life, including in the world of research which, as Kuhn (1970) elegantly demonstrated, is a socially-embedded phenomenon. In a recent editorial published in Organization, Parker and Thomas (2011, p. 419) maintain that critical scholars cannot escape from the ascendancy of contradiction:

The distributions of good and bad are rarely that well arranged. [...] [A]ny description of "the other" is a tricky business. In ideal type terms, the others of the critical people are positivists, functionalists or modernists, but also sometimes patriarchs, imperialists, and hetero-normative defenders of the US pro-growth managerial hegemony. Of course "we", who also mostly work in business schools, often use evidence and causation in our arguments, travel in aeroplanes, 
use iphones, and shop in supermarkets, might be accused of many of these sins too. We all live in glass houses, and should be careful where we throw stones.

How many critical accounting scholars go to international conferences by air, in order to present research which aims to cast doubt on multinationals' willingness to address the climate change problem? How many critical accounting scholars criticize the corporate behavior of Suncor, BP and others, while at the same time, have investments in these companies through their pension fund? How many of us own the shares of financial institutions that support companies involved in the oil sands business? On this basis, it may not be unreasonable to maintain that it would be very hard for human beings, including academics, to remove themselves, totally, from social contradiction.

Our conviction is that contradictions sustained and reproduced through institutionalized structures (such as journal rankings) should be studied and the inequalities and prejudices they engender and the interests which they serve, should be uncovered and denounced. Even though prevailing institutions tend to be solidly ingrained in society, critical researchers have a duty to investigate how institutions and their underlying contradictions exert power over individuals, groups and communities - promoting, for instance, homogeneity in the realm of thoughts and ideas. Critical researchers should aim to make individuals and communities aware of these processes, in order to provide them some means to modify the order of things, however difficult this may be. In particular, CPA's inclusion in SSCI constitutes a useful reminder that the critical accounting research community should not hesitate to investigate and disclose the damaging effects that today's obsession and excessive reliance on journal rankings can have - not only on researchers' individual lives and careers but also in terms of the challenges involved in protecting diversity of thought in the academic literature and work which challenges the status quo. Paradoxically, being included in SSCI may allow the articles that will be published in CPA, including those that cast doubt on journal rankings, to be more widely read, cited and, hopefully, be more influential in bringing about change. After all, Alvesson and Spicer (2012) maintain that the economy of persuasion which emphasizes the symbolic is one of the key features of today's society. Some "enhancing" effects, or at least opportunities to stimulate individuals' reflexivity, may ensue from CPA being part of SSCI. This is not the only contradiction we will ever see. Importantly, we need to continue to ask critical questions about the most important issues facing society and produce rigorous research designed to be used to bring about a better world.

The Editors,

Marcia Annisette, Christine Cooper and Yves Gendron 


\section{REFERENCES}

Adler, N. M., \& Harzing, A.-W. (2009). When knowledge wins: Transcending the sense and nonsense of academic rankings. Academy of Management Learning \& Education, 8(1), $72-95$.

Alvesson, M. (2013). The triumph of emptiness: Consumption, higher education \& work organization. Oxford, England: Oxford University Press.

Alvesson, M., \& Sandberg, J. (2013). Has management studies lost its way? Ideas for more imaginative and innovative research. Journal of Management Studies, 50(1), 128-152.

Alvesson, M., \& Sandberg, J. (2014). Habitat and habitus: Boxed-in versus box-breaking research. Organization Studies, 35(7), 967-987.

Alvesson, M., \& Spicer, A. (2012). A stupidity-based theory of organizations. Journal of Management Studies, 49(7), 1194-1220.

Funnell, W. (1998). Accounting in the service of the holocaust. Critical Perspectives on Accounting, 9(4), 435-464.

Garfield, E. (2006). The history and meaning of the journal impact factor. Journal of the American Medical Association, 295(1), 90-93.

Gendron, Y. (2008). Constituting the academic performer: The spectre of superficiality and stagnation in academia. European Accounting Review, 17(1), 97-127.

Gendron, Y. (2015). Accounting academia and the threat of the paying-off mentality. Critical Perspectives on Accounting, 26, 168-176.

Girard, R. (1965). Deceit, desire and the novel: Self and other in literacy structure. Baltimore, MD: Johns Hopkins University Press.

Guénin-Paracini, H., \& Gendron, Y. (2010). Auditors as modern pharmakoi: Legitimacy paradoxes and the production of economic order. Critical Perspectives on Accounting, 21(2), 134-158.

Hermanson, D. R. (2015). "Model 2"-A personal journey in pursuit of creativity and impact. Critical Perspectives on Accounting, 26, 130-140.

Hopwood, A. G. (2007). Whither accounting research? The Accounting Review, 82(5), 13651374.

Humphrey, C., \& Gendron, Y. (2015). What is going on? The sustainability of accounting academia. Critical Perspectives on Accounting, 26, 47-66.

Jeacle, I. (2012). Accounting and popular culture: Framing a research agenda. Accounting, Auditing \& Accountability Journal, 25(4), 580-601.

Komori, N. (2015). Beneath the globalization paradox: Towards the sustainability of cultural diversity in accounting research. Critical Perspectives on Accounting, 26, 141-156.

Kuhn, T. S. (1970). The structure of scientific revolutions ( $2^{\text {nd }}$ edition). Chicago, IL: University of Chicago Press.

Macintosh, N. B. (2002). Accounting, accountants and accountability: Poststructuralist positions. London, England: Routledge.

Malsch, B., \& Gendron, Y. (2013). Re-theorizing change: Institutional experimentation and the struggle for domination in the field of public accounting. Journal of Management Studies, 50(5), 870-899.

Malsch, B., \& Tessier, S. (2015). Journal ranking effects on junior academics: Identity fragmentation and politicization. Critical Perspectives on Accounting, 26, 84-98.

Messner, M. (2015). Research orientation without regrets. Critical Perspectives on Accounting, 26, 76-83.

Miller, P., \& O'Leary, T. (1987). Accounting and the construction of the governable person. Accounting, Organizations and Society, 12(3), 235-265.

Parker, M., \& Thomas, R. (2011). What is a critical journal? Organization, 18(4), 419-427. 
Pelger, C., \& Grottke, M. (2015). What about the future of the academy? - Some remarks on the looming colonisation of doctoral education. Critical Perspectives on Accounting, 26, 117-129.

Prasad, A. (2015). Liminal transgressions, or where should the critical academy go from here? Reimagining the future of doctoral education to engender research sustainability. Critical Perspectives on Accounting, 26, 108-116.

Rahaman, A., Neu, D., \& Everett, J. (2010). Accounting for social-purpose alliances: Confronting the HIV/AIDS pandemic in Africa. Contemporary Accounting Research, 27(4), 1093-1129.

Raineri, N. (2015). Business doctoral education as a liminal period of transition: Comparing theory and practice. Critical Perspectives on Accounting, 26, 99-107.

Roberts, J. (1991). The possibilities of accountability. Accounting, Organizations and Society, $16(4), 355-368$.

Roberts, J. (2009). No one is perfect: The limits of transparency and an ethic for "intelligent" accountability. Accounting, Organizations and Society, 34(8), 957-970.

Robson, K. (1992). Accounting numbers as "inscription": Action at a distance and the development of accounting. Accounting, Organizations and Society, 17(7), 685-708.

Sauder, M., \& Espeland, W. N. (2009). The discipline of rankings: Tight coupling and organizational change. American Sociological Review, 74(1), 63-82.

Tuttle, B., \& Dillard, J. (2007). Beyond competition: Institutional isomorphism in U.S. accounting research. Accounting Horizons, 21(4), 387-409.

Willmott, H. (2011). Journal list fetishism and the perversion of scholarship: Reactivity and the ABS list. Organization, 18(4), 429-442. 